\title{
A FORTALEZA PERDIDA DE FLAVIUS JOSEFUS $(*)$.
}

\author{
MARIZA BALSAMO STEINBERG \\ Instrutora da Cadeira de História Antiga e Medieval da \\ Faculdade de Filosofia, Ciências e Letràs da Untvers1- \\ dace de São Paulo.
}

Quando Josefus tomou o cargo de comandante da Galiléa, na primeira guerra romana, um de seus primeiros atos foi fortificar um número de cidades e lugarejos em posições estratégicas, para bloquear as possíveis rotas de ataques inimigos. A lista dos lugares assim fortificados foi dada duas vêzes, nos seus escritos: uma vez no Livro Segundo da Guerra Judáica (II, $\S \S 573-4$ ) e novamente, numa forma muito abreviada, na Vida ( $\S \S 187-188)$. A lista precendente

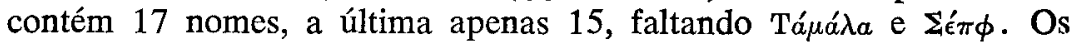
nomes estão, no total, melhor preservados na lista longa tendo a da Vida, pequenas corruptelas.

As duas listas formam uma importante adição ao nosso conhecimento da topografia histórica da Galiléia, no perío do Segundo Templo. Todos os nomes, exceto um, foram identificados, com concordância geral da maioria dos eruditos. Antes de propor uma identificação da fortaleza perdida, devem ser ditas umas poucas palavras, concernentes aos outros nomes, suas identificações e posições .

Três das fortalezas eram em Gaulan (Selêucia, Sogane, e Gamala) e podem ser despresadas, pelos propósitos dêste inquérito. Um estudo dos nomes remanescentes na Galiléia pròpriamente dita, mastra que Josefus colocou suas fortalezas com a intenção definida de criar uma espécie de linha fortificada ao longo das fronteiras da Gali-. léia. Está claro que cada fortaleza tinha uma tarefa específica, determinada pelo esbôço geral do terreno e a direção das linhas de comunicação convergindo para a Galiléia, porque, òbviamente, a futura invasão seguiria essas linhas. Assim nós encontramos um grupo de quatro fortalezas - a rocha de Acchbari (Akbara), Sepph (Safed), Iamnith (Khirbet Banit?) e Meroth (Mêrôn), que protegiam as rotas entre Jermaq, as montanhas Qadesh, o vale Amud e Monte Canaan

(*). - (Extraído do "Israel Exploration Journal", vol. 3, n? 2, 1953; tendo sido publicado em hebraico numa forma em EI, 1, 1951) Trađução de Mariza Balsamo Steinberg. 
em adição a uma quinta fortaleza, Gischala (el-Jish), a qual era mantida por João de Gischala, grande rival de Josefus. Um segundo grupo de fortalezas protegia as costas do mar da Galiléia (Tiberíades, Magdala-Taricheae e Arbel).

A longa linha que protegia a Galiléia do oeste, sudoeste e sul é de especial interêsse, primeiramente porque essa linha aparentemente contém o nome não identificado pelo qual estamos procurando, e secundàriamente porque êste era, a frente mais longa e mais exposta. Realmente seria mais provável que a invasão viesse tanto do oeste, a direção dos quartéis generais de Vespasiano em PtolemaisAccho, ou do sul, via o grande centro helenístico de Beth Shan56

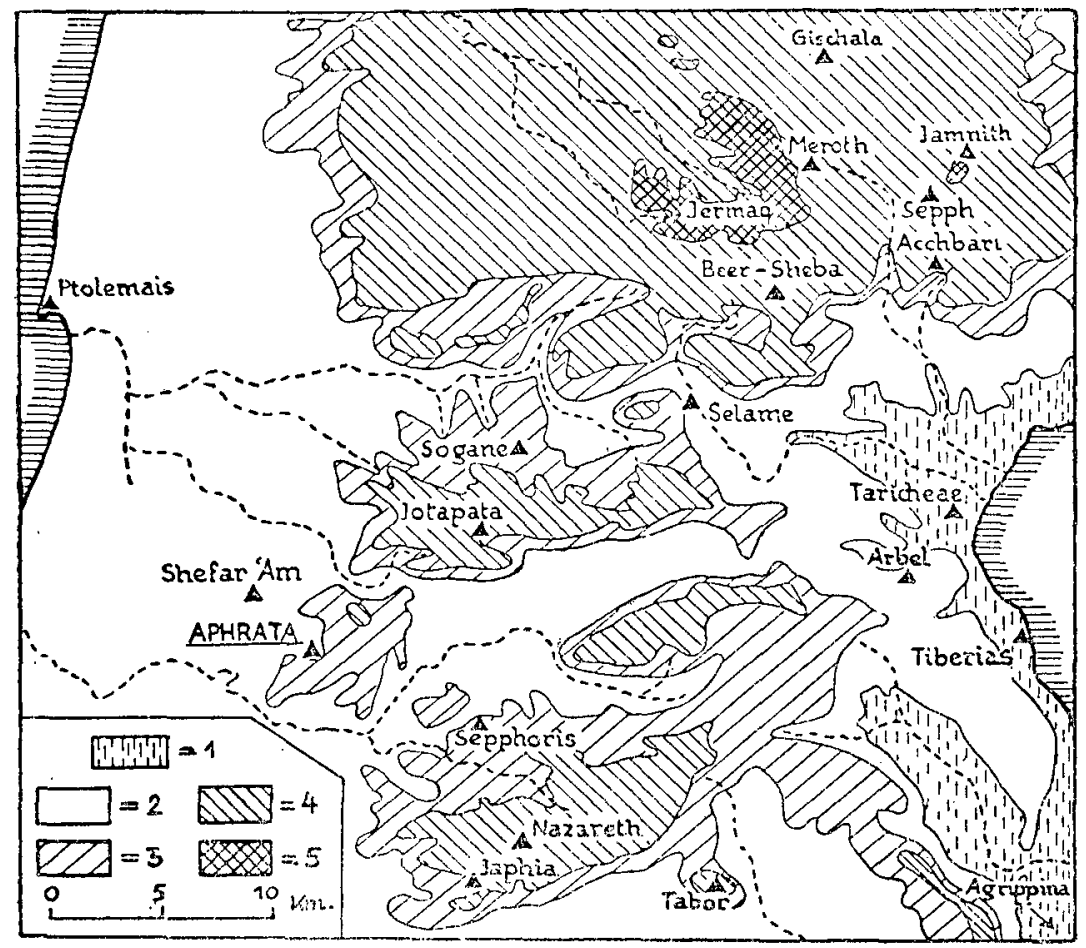

Scythopolis, que tinham sido hostís aos judeus desde o início da guerra (1). Como está evidente da história subsequiente, ambas as suposições estratégicas de Josefus provaram ser corretas; o primeiro ataque

(1), - B. J. II, $466 \mathrm{ff}$. 
veio do oeste, e foi seguido de um segundo golpe do sul, pela via de Scythopolis (2).

A linha começava no SE com a fortaleza de Agrippina (3) (Kaukabel-Hawa?), a qual Josefus não menciona, mas que deve ter sido o início da linha no oeste, porque, de outra forma, a seção do fronte entre Monte Tabor e a Jordânia estaria perigosamente aberta. Os pontos seguintes eram (de este a oeste) Monte Tabor, ('iтaßúpıv opo5) e Iaphia ("Ia $\phi a$ ), seguido por Sepphoris, o qual era fortificado por seus próprios habitantes. A linha do oeste continuava com Iotapata (I $\omega \tau \dot{a} \pi a \tau a$, Khirbet Shifat), a mais forte fortaleza da Galiléia, seguida ao norte por Beer-Sheba ( $\beta \eta \rho \sigma a \beta \hat{\epsilon}^{\prime}$, Khirbet Abu Shiba), e Selame ( $\Sigma \epsilon \lambda a ́ \mu \eta \eta$ Khirbet Sellamiya). Como vemos, a ordem geográfica não tem sido muito bem mantida aqui; nós podemos, para tal, adicionar o nome de Sogane (Sakhnin) que aparece de forma corrompida em uma das versões (4). Nesse grupo Beer-Sheba protegia a passagem sul de Jermaq; Selame, o vale do mesmo nome (Yôredet Sellamîn. (5) - agora o Wadi Rubadiye), Sakhnin e Iotapata, as passagens do vale Hilazôn à planície de Bêt-Netôfa, o coração da baixa Galiléia .

Uma olhada ao mapa (fig. 1) mostrará que êsse sistema de fortalezas protegia a Galiléia em tôdas as direções, exceto uma, havendo uma brecha evidente entre Iotapata e Sepphoris. O mais curioso é que uma das principais estradas da Galiléia passava nessa direção, viz., a rota de Ptolemais a Sepphoris, a qual foi posteriormente substituída pela estrada romana (6) e, no presente, pela estrada Shefar'am-Nazareth. Assim, parece muito improvável que Josefus tivesse deixado essa importante linha sem proteção - especialmente uma que ia diretamente em direção aos quartéis-generais de seus inimigos e ponto de concentração, viz. Ptolemais-Accho, parece óbvio, a priori, que tenhamos que procurar nessa região, o nome perdido.

Agora nós encontramos na lista das fortalezas, mais um nome que foi transmitido numa forma muito corrompida. Ele aparece entre Iaphia e Selame, mas, como já vimos, a ordem geográfica dessa lista não é muito válida. Esse nome aparece nas seguintes formas nas várias versões (de acôrdo com Niese):

(2). - BJ III, $155 \mathrm{ff}, 446 \mathrm{ff}$.

(3). - Misna Rôs ha-Sana if, 4; Dalman, PJB, 1923, p. $43 \mathrm{f}$.

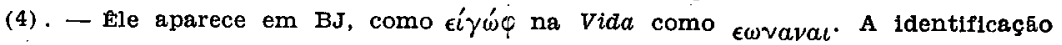
comum é com "Uyun esh-Sha'ab", perto do Monte Tabor, mas a Identificaçá com Sogane-Sakhnin (Vida 265) parece preferível; tal fortaleza preencheria muito bem a brecha. entre Iotapata (tambem conhecida como Jotapata) e Selame enquanto uma em "Uyun esh-Sha'ab, perto do Monte Tabor, parece supérflua.

(5) . - Misna Kela1m iv, 9.

(6) . - QDAP, 12, 1946, p. 96. 


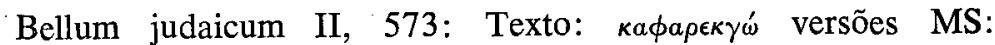

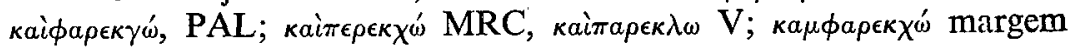
m.l L; Capherecho Lat.

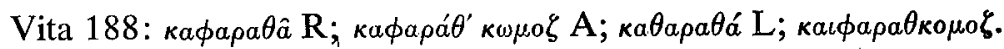

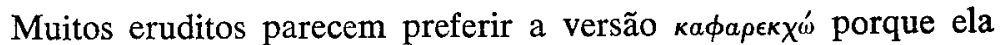
pode ser fàcilmente identificada com Kefar 'Akkô de Tôseftâ (7).

Hildesheimer identificou o local como 'Amqa (8), enquanto Saarisalo propôs, com melhores bases, identificá-lo como Tell-elFukhkhar, perto de Acre (9). Se nós aceitarmos essa identificação, a fortaleza de Josefus não pode ser identificada com Kefar 'Akkô. Josefus dificilmente estaria disposto a fortificar um local nos subúrbios de Accho-Ptolemais, o quartel general do inimigo! Oehler (10) e Abel (11), não sugerem nenhuma identificação por êsse "Caphareccho".

Parece que a melhor versão foi preservada em Vida (Vita).

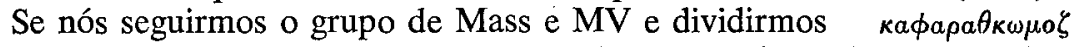

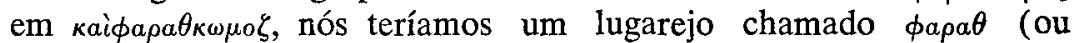

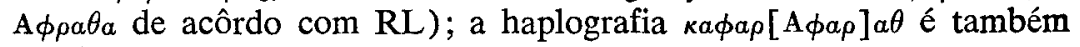
possível.

Nomes como Aфapata eram muito comuns no tempo do Segundo Templo, e apareciam em várias formas tais como Ephreae, Pharath, Pharathon, Ophra, Ephraim, ou Ephron. O grego A фapaAa corresponderia ao 'frt semita. Se começarmos a olhar um plausível correspondente árabe para um nome composto desta raiz, nós chegaríamos imediatamente ao curioso fenômeno conhecido como Tayybetismo. Para os árabes a raiz 'frt é ligada ao significado "mal espírito" ou "demônio" e êles mudaram sistemàticamente tais nomes para "Tayyibet-el-Ism" ("de bom nome") ou et-Tayybe, para encurtar.

Se nós olharmos agora no mapa da Topografia de Israel (1:100.000 sheet 2$)$, nós encontraremos em 196243 uma Khirbet-etTayyibe no caminho de Shefar'am a Nazareth ou Sepphoris. Parece que a identificação dêste local com a fortaleza perdida de Josefus, devido a estarem ambas em locais estratégicos e devido à semelhança do nome, é mais plausível.

(7). - Tôseftâ Kelâim 1, 12 (ed, Zuckermandel, p. 74. 1. 14).

(8) . - Beiträge, pp 19-20; cf. também P. Romanoff: "Onomasticon of Palestine". N. York, 1937.

(9) . - JPOS, 9, 1929, p. 28 .

(10). - ZDPV, 1905, p. 63.

(11). - Géographie de la Palestine, II. Paris, 1938, pp. 289-290. Abel aponta justamente que o lugar deve ser encontrado entre Iaphia e Iotapata e adiciona: "difficllement 'Akrus'.

(12). - Dr. N. Avigad preparou o desenho. 
Passemos às considerações arqueológicas: o local era certamente aquêle de um lugarejo judeu da éra Talmúdica, testemunham os restos de uma sinagoga, já observado aí pelo levantamento topográfico de 1873:
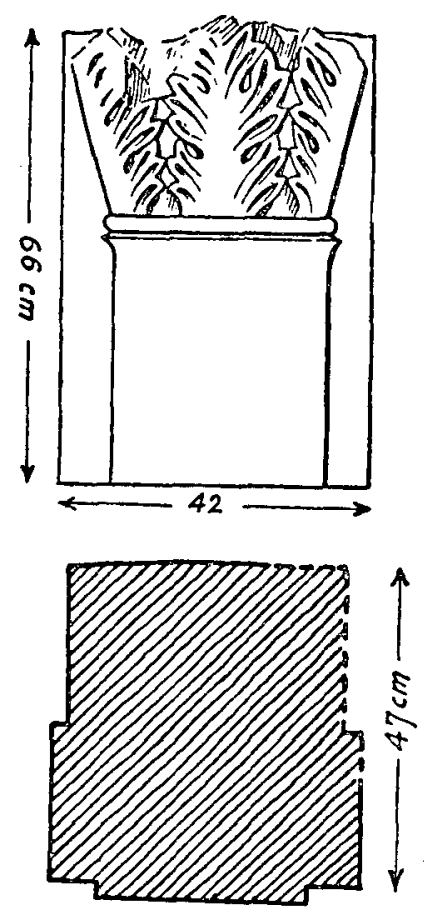

"êste foi um lugar de alguma importância. Tem um poço de boa água, e, uma fonte, ao sul, ... Acima do poço fica barragem coberta de alvenaria caída e alicerces. ... O poço é uma base de coluna de dois cantos semelhante às encontradas em sinagogas da Galiléia: ... Há outros pontos semellantes nas ruínas; e uma sinagoga provàvelmente aí ..." (13).

Numa visita ao local em julho de 1952, encontramos alicerces e pedras ainda próximos ao poço, como foi descrito em Survey, além de uma pequena elevação paralela em outra sinagoga da Galiléia

(13). - Survey of Western Palestine, Mem. I, London, 1881, p. 321. - Pelo que eu sel eruditos posteriores não tomaram conhecimento do local. 
(Fig. 2). Muitas pedras (empregadas em construção) foram encontradas no local, e uma barragem, eram observadas as fundaçōes de um longo muro, os restos de um edifício de alguma importância. Devido à curta exposição, só um exame superficial da cerâmica pode ser feito. Embora a êsse respeito a evidência não seja completa, a posição estratégica do local é mais expressiva. Situa-se numa montanha isolada ao sul da estrada (caminho), dominando um vasto panorama a oeste, de cujo lado o inimigo viria. Parece a mais adeqüada posição para a localização da fortaleza perdida de Josefus. 